\title{
Variation in the orographic extreme rain events over the Meghalaya Hills in northeast India in the two halves of the twentieth century
}

\author{
Pawel Prokop • Adam Walanus
}

Received: 9 September 2013 / Accepted: 5 July 2014 / Published online: 9 August 2014

(C) The Author(s) 2014. This article is published with open access at Springerlink.com

\begin{abstract}
The daily rainfall data for the twentieth century, from three stations across the region, constitute the basis for statistical analysis. However, the low signal-to-noise ratio makes it difficult to find any significant departure from the simplest null hypothesis of the stability of the rain record at individual stations in northeast India. Only the coarsest possible view, i.e. comparing the two halves of the century, provided strongly significant results in the numbers of days with extreme rain. Using a more general approach, the number of Fourier transform extreme amplitudes also differed significantly. Increasingly heavy events during the summer monsoon season, and partly in the pre- and post-monsoon seasons, are offset by a weakening in the winter monsoon season, so that the annual mean rainfall does not show a significant trend over the Meghalaya Hills. Apart from a greater number of years with noticeable extreme rainfall events in the second half of the twentieth century, we can also observe a more pronounced quasi-periodicity of 10-20 and 30-60 days during the same period. The detection of the latter periodicity indicates that the Madden-Julian oscillation plays an important role in the formation of extreme rainfall events over the Meghalaya Hills during extreme monsoon years.
\end{abstract}

\section{Introduction}

Climate model studies show that an increase in global surface temperature, as a result of the increase in greenhouse gases,

\author{
P. Prokop $(\bowtie)$ \\ Department of Geoenvironmental Research, Institute of Geography \\ and Spatial Organization, Polish Academy of Sciences, Jana 22, \\ 31-018 Krakow, Poland \\ e-mail: pawel@zg.pan.krakow.pl
}

A. Walanus

Department of Geoinformatics and Applied Computer Science, AGH

University of Science and Technology, Krakow, Poland can lead to an increase in the magnitude and frequency of extreme precipitation events (Hennessey et al. 1997; Meehl et al. 2000; Trenberth et al. 2003; IPCC Intergovernmental Panel on Climate Change 2007). The severe rains have a substantial socio-economic impact in tropical areas which are dependent on agriculture and prone to natural hazards such as flooding and mass movements. Thus, in recent decades in India, many authors have analysed extreme rainfall series for periods of different lengths, using data from different rain-gauge networks and a variety of methods (Rakhecha and Soman 1994; Dhar and Nandargi 1995; Roy and Balling 2004; Goswami et al. 2006; Rajeevan et al. 2008; Guhathakurta et al. 2011).

Northeast India, where the Meghalaya Hills are located, can be treated as a relatively separate region, with summer monsoon rainfall weakly correlated or out of phase with that of peninsular India (Mooley and Shukla 1987; Parthasarathy et al. 1987; Sontakee and Singh 1996; Guhathakurta and Rajeevan 2008; Guhathakurta et al. 2011). The area receives high rainfall (the annual mean approximately 2,066 $\mathrm{mm}$ with a coefficient of variation of $8.6 \%$ ), but its large spatiotemporal variation, related to multiscale interaction with topography, results in difficulties in the detection of trends in extreme rain events (Parthasarathy et al. 1995; Goswami et al. 2010). Trend analysis for the annual and seasonal rainfall series thus shows these to be very stable, with no change in the rainfall in NE India during at least the past 150 years. These stable conditions are seen not only on a regional scale but also at subdivision and station levels (Prokop and Walanus 2003; Dash et al. 2012; Jain et al. 2013). Dash et al. (2009), using highresolution daily gridded rainfall data for the period 19512004 , examined the changes in the number of rain events of different durations and intensities in the whole of India as well as over its homogeneous regions. They found that the frequency of heavy rain days and moderate rain days increased and decreased, respectively (significant at $5 \%$ level), in 
northeast India in both the monsoon and post-monsoon seasons. Further study of changes in the long and short spells of different rain intensities shows that short spells of heavyintensity rain have risen and those of moderate intensity have decreased during the summer monsoon over northeast India in the past 50 years (Dash et al. 2011). However, it should be mentioned that Goswami et al. (2010), in their analysis of daily rainfall data from 15 stations between April and October in NE India, for the period from 1975 to 2006, found a decreasing trend of extreme events with more than $150 \mathrm{~mm}$ rainfall per day and that this exceeded the 99th percentile. This is in contrast to a detected increasing trend of such events in central India (Goswami et al. 2006) and in the whole of India (Dash et al. 2009; Dash et al. 2011).

The interaction between large-scale circulation and the local topography plays a crucial role in determining the spatial distribution of rainfall over the Meghalaya Hills (Prokop and Walanus 2003; Murata et al. 2007). They form the first orographic barrier for the humid southwest monsoon winds, on their way from the Bay of Bengal to the Himalayas (Fig. 1). The annual rainfall distribution pattern is strongly controlled by the southern escarpment of the Meghalaya plateau. It varies from $6,000 \mathrm{~mm}$ in the southern foothills to 11,000 $12,000 \mathrm{~mm}$ (the average summer monsoon total $8,408 \mathrm{~mm}$ ) in Cherrapunji (1,300 $\mathrm{m}$ a.s.l.). Rainfall then decreases with distance from the southern edge of the plateau, to $2,200 \mathrm{~mm}$ (the average summer monsoon total $1,470 \mathrm{~mm}$ ) in Shillong (1,598 $\mathrm{m}$ a.s.1.) and only $1,600 \mathrm{~mm}$ (the average summer monsoon total $1,074 \mathrm{~mm}$ ) in Gauhati (54 m a.s.1.), located in the Brahmaputra valley. About $80 \%$ of the annual rainfall occurs between June and September. The Meghalaya Hills represent only $2 \%$ by area of the Ganges, Brahmaputra and Meghna basins, though they account for about 20-25\% of the rainfall input between March and June (Hofer 1997). The rainfall over the southern slopes of the Meghalaya Hills is thus very important in the flood processes noted in Bangladesh (Hofer and Messerli 2006; Murata et al. 2008). Dhar and Nandargi (2000) also include the northeast as being among the flood-prone areas in which the majority of floods in India occur.

Studies at individual stations over the Meghalaya Hills have concentrated mainly on the very high rainfall at Cherrapunji (Dhar and Farooqui 1973; Thapliyal and Kulshrestha 1992; Dhar and Nandargi 1996; Starkel and Singh 2004; Guhathakurta 2007; Murata et al. 2007; Soja and Starkel 2007). Cherrapunji holds the world record for high rainfall, which is of durations of between 31 days and 2 years, over the period of 150 years. Between August 1860 and July 1861, the station recorded $26,461 \mathrm{~mm}$ of rain (Jennings 1950). Most authors agree that orography is the main cause of the enormous rainfall at this station. However, other factors which support enhanced rainfall are also mentioned, such as the location of a monsoon trough in the foothills of the Himalayas, favouring a lifting of the southerly flow over the steep southern side of the plateau (Murata et al. 2008); additional moisture extraction over the Bangladesh wetlands during the flow of maritime moisture into the region from the Bay of Bengal (Medina et al. 2010); and the maximization of the synoptic-scale low-pressure anomaly over the Meghalaya (Romatschke and Houze 2011a). Recent analyses of the $\delta^{18} \mathrm{O}$ and $\delta \mathrm{D}$ stable isotope content of rainwater from Cherrapunji indicate that the monsoon air masses reach Meghalaya mainly from the Bay of Bengal and, to some extent, from the western part of the Arabian Sea (Breitenbach et al. 2010). The northern Bay of Bengal is an especially important source of the moisture transported over the Meghalaya Hills.

This study aims to carry out a statistical analysis of the temporal variability of extreme daily rainfall events over the Meghalaya Hills during the twentieth century. Attention is also paid to the role of the mountain barrier in changes in the spatial distribution of extreme rainfall during different seasons.

\section{Data}

The analysis of the temporal variability of rainfall was carried out using data from the stations at Cherrapunji, Shillong and Gauhati. These represent three contrasting areas of the Meghalaya Hills, located across the plateau, along the SW and NE monsoon circulations, and the path of tropical cyclones. Daily rainfall data (1901-2000) for the three stations were obtained from the National Data Centre of the Indian Meteorological Department (IMD), Pune. Gaps in the data were filled by copying directly from the journal records available at the Regional Meteorological Centre, in Gauhati, and the historical daily rainfall records for India, printed annually by the Meteorological Department.

Row examination of the time series referred to indicates no evidence of any pattern in the range of medium and high frequencies. The departure from the null hypothesis of the stability of the rain record found at the lowest frequency band is not very strong, necessitating the very clear stating and fulfilling of the assumptions for the statistical tests applied. This is why the simplest possible method of time indication has been used. The daily rainfall data for the time span 1901-2000 were divided into two halves, 1901-1950 and 1951-2000, in order to search for any differences. This does not mean that there is any strong boundary exactly at 1950 . However, we were able to detect that the two halves are different and a finer division, into quarter centuries, reveals no new information in the rainfall pattern. 
Fig. 1 Location of the Meghalaya Hills, with N-S cross-section and seasonal rainfall distribution for the period 1901-2000. Stations: G Gauhati, $S$ Shillong, $C$ Cherrapunji; Seasons: $A$ winter, $B$ premonsoon, $C$ monsoon, $D$ post-monsoon
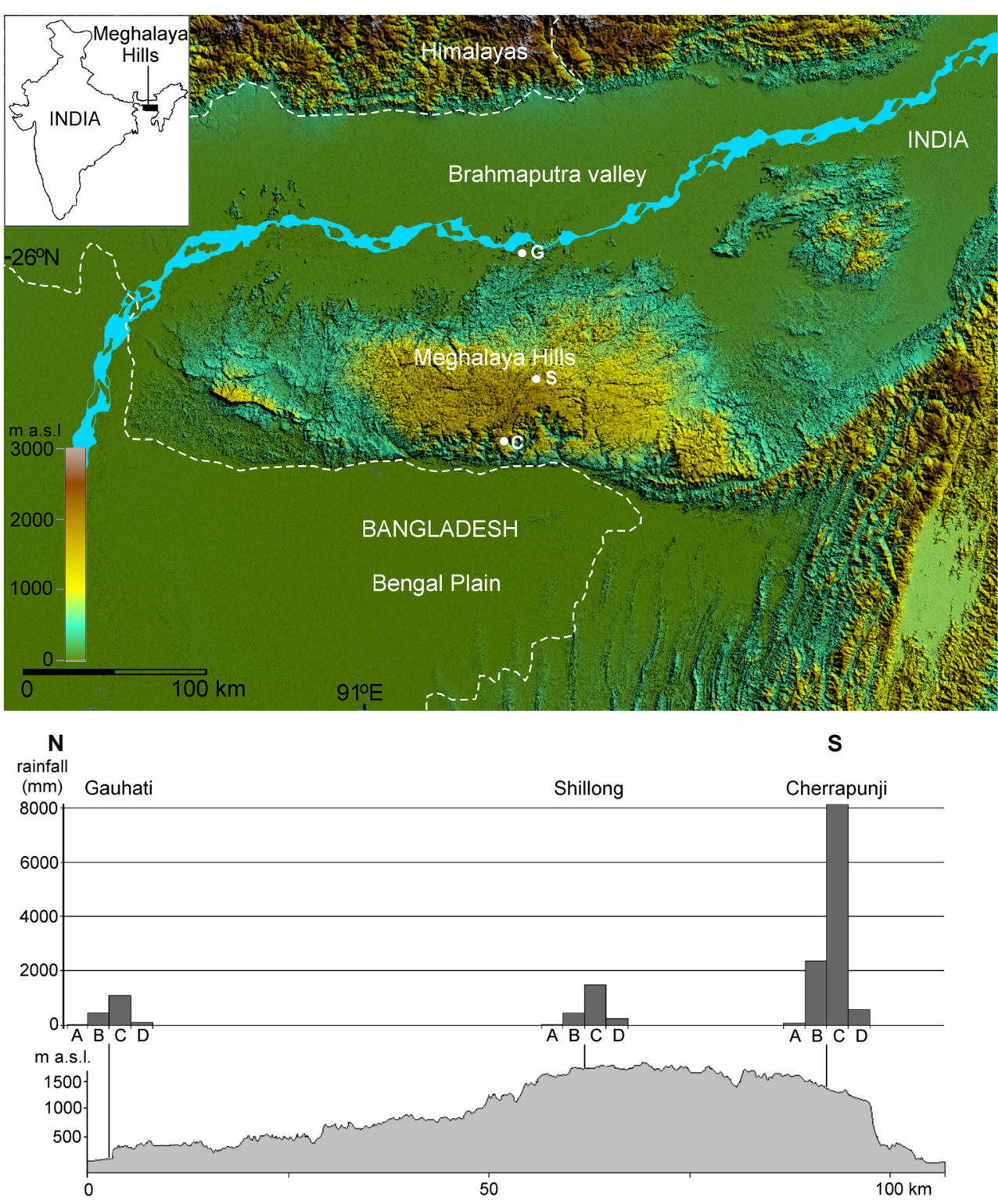

Analysis was performed independently for the four climatic seasons that can be distinguished over northeast India (Rao 1981a): winter (January-February), premonsoon (March-May), southwest monsoon (JuneSeptember) and post-monsoon (October-December).

\section{Statistical analysis}

The variable to be statistically treated was the number of days in which the rainfall $(\mathrm{mm} /$ day) fell into a specified range. The authors decided to apply five boundaries, 5, $10,50,100$ and $200 \mathrm{~mm}$, which offered six nonoverlapping classes. This wide range includes all the three stations which differ in average daily rainfall during the period 1901-2000: Cherrapunji $31.2 \mathrm{~mm}$, Shillong
$6.1 \mathrm{~mm}$ and Gauhati $4.5 \mathrm{~mm}$. Since the two halves of the century for each station were compared separately, it presents no problem that the presented numbers are distinctly unequal.

As an example, at Cherrapunji, the number of days with rainfall above $200 \mathrm{~mm}$ during monsoon time, in 1901-2000, was 1,062. The actual number of days for $1951-2000$ is 584 . The latter number is higher than half of that for the whole century $(584>531=1,062 / 2)$; the only question is whether it is significantly higher, statistically. For statistical testing, the null hypothesis is necessary. In this case, it is natural to state $\mathrm{H}_{0}$ as being that the expected numbers of days in the two halves of the century are equal. To perform a test, it has to be assumed that the number of days conforms to the binomial probability distribution. The 1-week point of that assumption, 
namely that the total number of days above $200 \mathrm{~mm} /$ day, during the whole century, is also a random variable, was checked by the Monte Carlo experiment that draws no significant interference in the case of numbers of events, such as in the example presented.

The probability (in one sense, it is the so-called $p$ value) was calculated for the random event, defined as attaining the observed number of days (478) or smaller, assuming the total number of days $(1,062)$, and the probability of 0.5 of the random contribution of the day to the second half century. The obtained probability was transformed into the standardized normal variable, for better intelligibility, on account of the fact that the probabilities obtained were also very low, which would require many zeros to be presented.

It is worth remembering that, in the case of the normally distributed variable, the probability of being lower than -1 or higher than 1 is 0.32 and, for larger deviations, the probabilities are $2-0.046,3-0.0027,4-0.000063$ and $5-$ 0.00000057 . Accordingly, for absolute deviations larger than 2 , statistical significance is reached, assuming $\alpha=0.05$.

The results are presented in Table 1, for all the three stations and four climatic seasons.

\subsection{Winter}

Atmospheric circulation over the Meghalaya Hills in winter is under the influence of the cool, dry winds of the NE monsoon. Winter is the only season when statistically significant increases in the rainfall events in any of the defined thresholds do not appear. The most significant value $(z=-5.0)$ is observed for the reductions in light rainfall events $(0$ $5 \mathrm{~mm} /$ day) at Cherrapunji. Also significant is a reduction in light and moderate rainfall events (5-50 mm/day) at Shillong, which is the most exposed to the winds of the NE monsoon. At the same time, the total rainfall at Cherrapunji station is twice as high as that in Shillong and Gauhati. We can therefore presume that the local circulation plays an important role in rainfall generation over the southern slope of the Meghalaya, during the winter season. In the case of the Gauhati station, no univocal tendency in rainfall structure is visible.

\subsection{Pre-monsoon and post-monsoon}

Tropical cyclones, apart from convective rainfall caused by mesoscale forcing, form an important feature of the weather over northeast India including the Meghalaya Hills during pre- and post-monsoon seasons (Rao 1981b; Subbaramayya and Rao 1984; India Meteorological Department 2008; Singh et al. 2011). Seasonal distribution of tropical cyclones is related to the seasonal variations in the location of the monsoon trough over the Bay of Bengal (Alam et al. 2003). Migration of the trough above open water facilitates the formation of depressions that sometimes initiate tropical

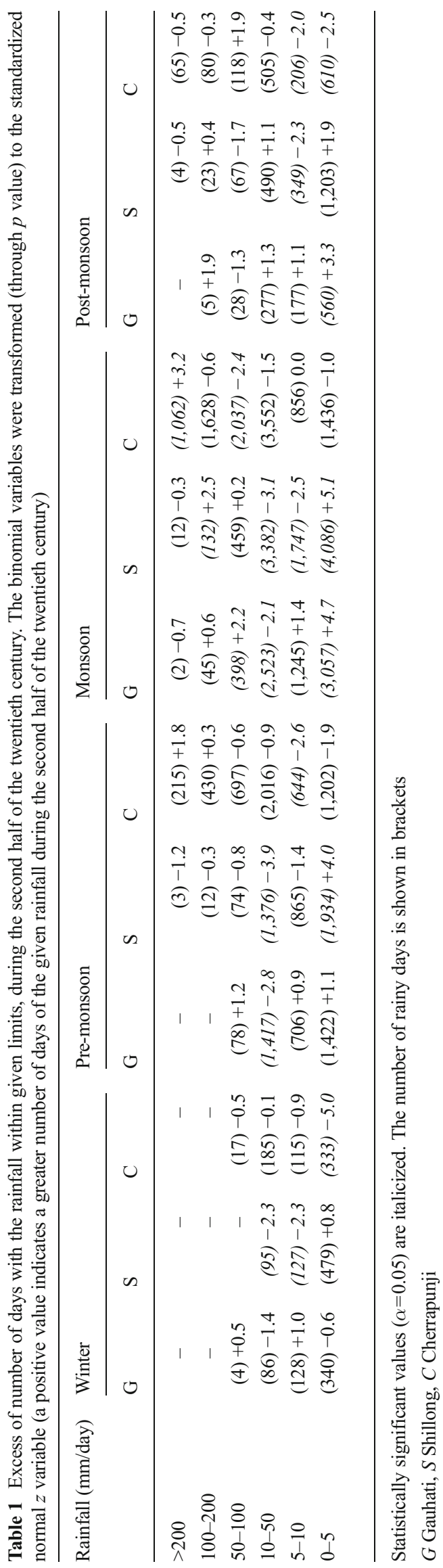


cyclones which move northward to the Bangladesh coast. Higher daily rainfall rates in the pre-monsoon season, as compared to the post-monsoon season (Fig. 2), are related to the short, intense convective downpours that occur more frequently between the end of March and May (Terao et al. 2008; Goswami et al. 2010). This progressive change in rainfall character, from more convective to less convective with a growing contribution of light rains, is already visible at the end of the summer monsoon season and is continued during the post-monsoon season (Romatschke et al. 2010; Romatschke et al. 2011b).

At Cherrapunji, the changes in frequency of the rainfall pattern show a significant $(z=-2.6)$ reduction in light rains, and a close-to-significant $(z=1.8)$ increase in heavy rains, in the pre-monsoon season. A close-tosignificant increase in the frequency of extreme rain events at Cherrapunji probably reflects an increase in the trend of cyclone frequency over the North Indian Ocean, including the Bay of Bengal, during the past few decades (Singh et al. 2000; Webster et al. 2005). Significant increasing trends were observed during November and May, which are the main cyclone months. Moreover, the frequency of severe cyclones has increased at a faster rate, at approximately $20 \%$ per hundred years. However, an increase in the frequency of heavy rains is not clearly visible during the pre- and post-monsoon seasons at Shillong and Gauhati. This is probably because the steep southern slope of the plateau acts as a sufficiently resistant barrier to the cyclone, which thus has to expend its energy. Hourly monitoring of spatial variability in the amount and intensity of rainfall during the Sidr cyclone (15-16 November 2007) showed that the windward area at Cherrapunji recorded $205 \mathrm{~mm}$ of rainfall in $40 \mathrm{~h}$, whereas the leeward area close to Gauhati recorded only $7.5 \mathrm{~mm}$ of rainfall in $11 \mathrm{~h}$. During the cyclone, the total amount of rainfall diminished from Cherrapunji, northwards, across the plateau from the windward side, at a rate of $0.81 \mathrm{~mm} / \mathrm{km}$ with an intensity of $0.254 \mathrm{~mm} / \mathrm{h} /$ $\mathrm{km}$ (Singh et al. 2011). This influenced the saturation vapour pressure and consequently changed the rainfall pattern over space. Thus, severe cyclones can cause extreme rainfall at Cherrapunji, but only light rainfall at Gauhati at the same time. These observations are also confirmed by Tropical Rainfall Measurement Mission (TRMM) data, showing a narrow zone (only approximately $20 \mathrm{~km}$ wide) of the highest pre-monsoon mean daily rainfall that is limited to the higher elevated central and southeastern edge of the plateau on which the Cherrapunji station is situated (Fig. 2).
Fig. 2 Mean daily seasonal precipitation ( $\mathrm{mm} /$ day), constructed using the Tropical Rainfall Measurement Mission (TRMM) 2B31 from 1998 to 2009 at $5 \mathrm{~km}$ spatial resolution (Bookhagen unpublished) for a winter, $\mathbf{b}$ pre-monsoon, $\mathbf{c}$ monsoon and $\mathbf{d}$ post-monsoon. The white dots indicate rainfall stations (cf. Fig. 1)
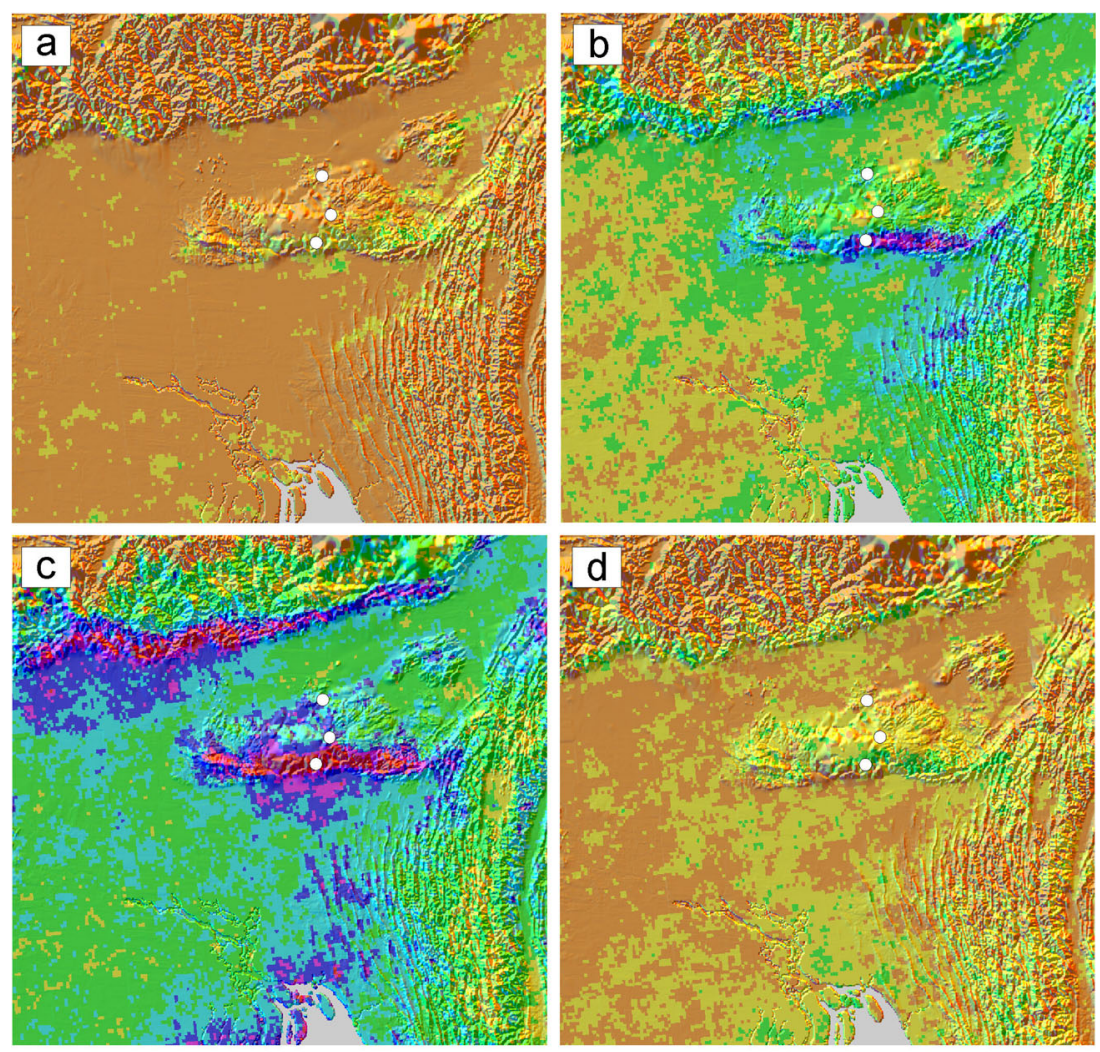

$\overline{0 \quad 100 \mathrm{~km}}$

$0-2 \square 2-5$

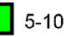

$10-15$

$15-20$ 20-25

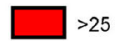




\subsection{Monsoon}

The summer monsoon is the only season in which the growth of the number of rainfall extreme days is statistically significant (the normal variable $z=3.2$, for Cherrapunji). The rainfall pattern of all the stations is highly influenced by the southerly and southwesterly winds. This is especially visible in the case of Cherrapunji, with only 13 days without rain, on average, during the 4 months of the summer monsoon. The frequency of heavy events $(>200 \mathrm{~mm} /$ day $)$ at Cherrapunji shows a significant increase, whereas that of moderate and light rain shows a slight $(z=-0.6 ; z=$ $-1.5)$ or significant $(z=-2.4)$ reduction. The Shillong and Gauhati stations thus show a similar pattern, with a significant increase in heavy and light events, and a significant reduction in moderate ones. The increase in the number of days with a very small amount of rain (0-5 mm/day) is the most statistically significant result obtained in this study, with $z=5.1$ for Shillong and $z=$ 4.7 for Gauhati $(z=5$ means $p$ value $=0.0000006)$.

The increase in the frequency of extreme rain events is consistent with a detected increasing trend of high rainfall events over central India (Goswami et al. 2006) and over the whole of India, including northeast India (Dash et al. 2009), as well as with model studies (Kitoh et al. 1997; Meehl et al. 2000; Trenberth et al. 2003, IPCC Intergovernmental Panel on Climate Change 2007). A discrepancy with the detected decreasing trend of extreme events in northeast India by Goswami et al. (2010) resulted from differences in the period of data used (32 years between April and October) and the method of defining extreme rain events (the number of events in exceedance of the 99th percentile and daily rainfall of above $150 \mathrm{~mm}$ ). Also, data from Cherrapunji station were not analysed in the mentioned paper. On the other hand, the significant decreasing trend is observed in the moderate rain days at all three stations. These results agree with those reported by Goswami et al. (2006) where they considered the limiting values for moderate rain day as 5 to $100 \mathrm{~mm} /$ day. Dash et al. (2009) also concluded that the frequency of moderate rain days decreased (but not significantly) over northeast India.

The increase in the frequency of extreme events can be associated with more warming of equatorial Indian Ocean than northern latitudes of the tropics that reduced vertical wind shear over the northern Indian Ocean and is thus responsible for the intensified activity of the strongest cyclones (Elsner et al. 2008; Krishna 2009). However, a significant reduction of moderate rain events can be the effect of the weakening of the summer monsoon circulation related to the reduction of the strength of the wind field over peninsular India and the adjoining southern parts of the Bay of Bengal in the second half of the twentieth century (Dash et al. 2009).

\subsection{Propagation of the high rainfall}

The propagation of the high rainfall from the southern edge of the plateau (Cherrapunji) northward into Shillong and Gauhati is evident. Some light on the relation between stations is shed by the correlation of rainfall intensity. However, in order to highlight the same interesting pattern, only the monsoon season was taken into account. The Pearson correlation coefficient was calculated for only those days when both the correlated sites had approached the given limit. Because Cherrapunji had almost exactly five times the rainfall of Shillong, the limit for Cherrapunji is five times that given in Fig. 3 (and applied to Shillong and Gauhati).

The correlation coefficients presented in Fig. 3 are relatively precise, on account of the large number of data points, with the exclusion of the case of the highest applied rainfall limits of 64 and $128 \mathrm{~mm} /$ day, since there were few corresponding days. As is evident, one feature of the result (Fig. 3) is the consequent lowering of the correlation with the increasing rainfall limit. The high correlation of 0.55 for light rainfall events between Cherrapunji and Shillong probably reflects the large stratiform rainfall systems which developed over the Meghalaya during the monsoon season (Romatschke et al. 2011b; Goswami et al. 2010; Romatschke et al. 2010). These large systems, with irregularly embedded convective cells enhanced locally by orographic lifting, produce high rainfall within an approximately $40-\mathrm{km}$-wide zone (twice as wide as in the pre-monsoon season) at the southern part of the Meghalaya. The highest rainfall is thus weakly correlated between the Cherrapunji station and that at Shillong, which

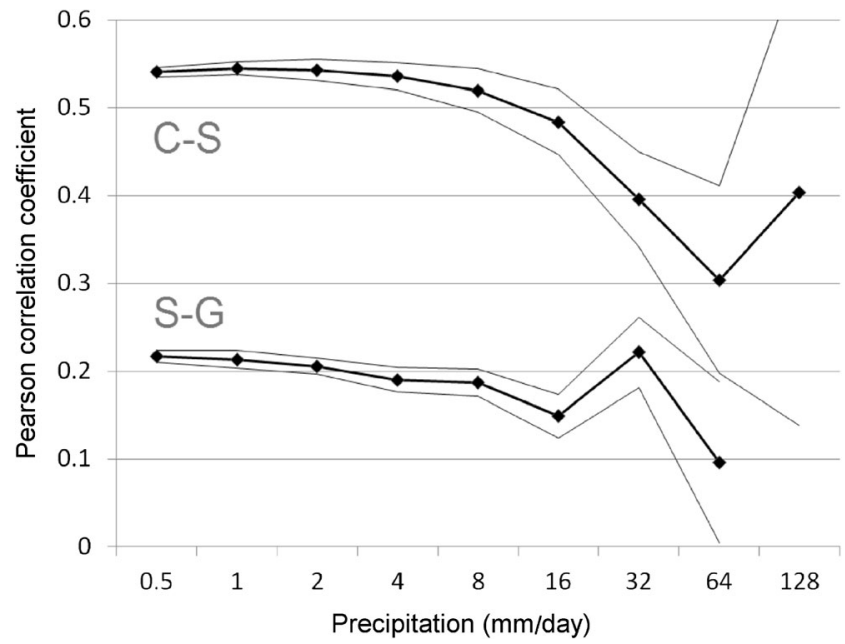

Fig. 3 Pearson correlation of daily rainfall between Cherrapunji and Shillong $(C-S)$ and Shillong and Gauhati $(S-G)$, in the monsoon season, calculated for days when both correlated stations had more rain than the limit presented on the horizontal axis; for Cherrapunji, the limit is actually assumed to be five times larger, in order to equalize the three stations. The thin lines are the $\pm 1 \sigma$ limits calculated by the bootstrapping method ('rainfall above some limit' is the random variable, by no means normally distributed, which excludes the standard significance calculation) 
is located at the northern margin of this zone. Consequently, Gauhati, together with the Brahmaputra valley, is out of the range of enhanced orographic lifting, so it rarely experiences extreme rains.

The light rainfall (below $5-10 \mathrm{~mm} /$ day) at Shillong is also weakly correlated with the rainfall at Gauhati, located on the leeward side of the Meghalaya Hills. This finding suggests that the increasing trends in the light rainfall at Shillong and Gauhati in all seasons except winter can be the mesoscale phenomena. It was found that convective heating associated with the synoptic events interacts with the Himalayas and generates southward-propagating gravity waves with a period of about $24 \mathrm{~h}$ in northeast India (Goswami et al. 2010). The strong updrafts associated with these waves produce deep convection and rainfall, especially at stations located in Brahmaputra valley such as Gauhati. It is important to note the absence of gravity waves at Shillong located on top of the Meghalaya Hills.

Direct observations and satellite measurements also indicate that urban areas are more likely to experience rainfall compared to nonurban areas. The effect of urban-induced rainfall was observed in northern Bangladesh (Yamane et al. 2010) and urban areas in India (Kishtawal et al. 2010; Mitra et al. 2012; Vittal et al. 2013). Both Shillong (the capital of Meghalaya with a population of 350,000 in 2011) and Gauhati (the capital of Assam with a population of 968,000 in 2011) are two of the most rapidly growing cities in India during the second half of the twentieth century. Changes in their urbanrural boundaries can have a feedback on the spatiotemporal patterns of rainfall. This aspect needs further examination based on the land use and population changes as well as observations of mesoscale and local weather systems over northeast India.

\subsection{Instability of the pink noise spectrum of the summer monsoon rainfall}

In searching for some general spectral structure in the rainfall, the fast Fourier transform (FFT) was applied to check if the data were close to white, red or pink noise (Fig. 4). Each monsoon season of all the 100 available years was independently FFT transformed. It appeared that, while very close to those of the pink noise, the spectra were less smooth in the second half of the twentieth century. The number of amplitudes above some defined level was treated as a measure of rainfall time series instability of some kind. It is not a question of systematic periodical patterns, however. The frequencies of higher amplitudes change from year to year. What is evident is that there are more seemingly 'spectral lines' in the second half of the twentieth century. That corollary needs to be statistically proved.

The fast Fourier transform was applied to each year independently of the 128-day-long monsoon period. The time

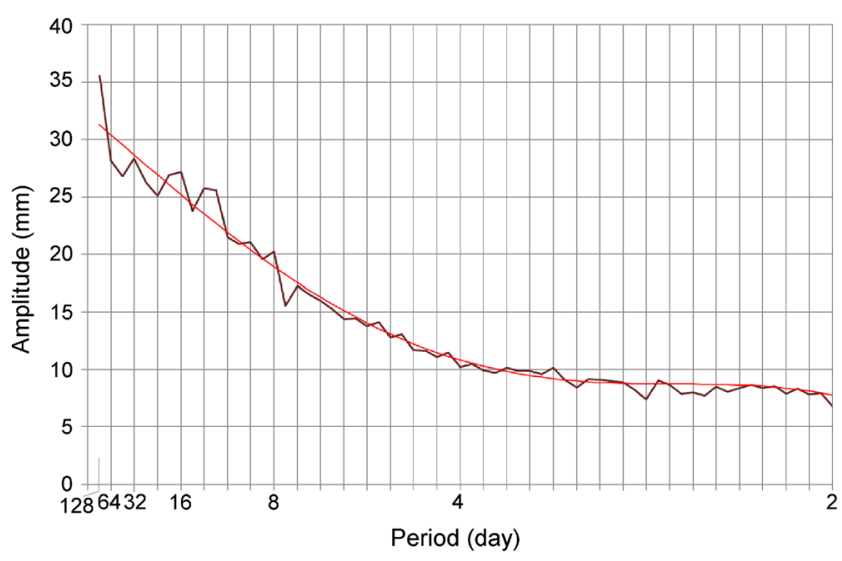

Fig. 4 Spectrum of the daily rainfall in the monsoon period at Cherrapunji. The experimental line is the average calculated from 100 individual spectra obtained from the individual monsoon years. The polynomial model: $A=-3.7 \times 10^{-6} \times d^{4}+0.39 \times 10^{-3} \times d^{3}-2 \times 10^{-3} \times d^{2}-$ $0.88 \times d+32$

series length, equal to the power of 2, is good for the FFT algorithm, for numerical reasons, and is almost precisely the length of the monsoon period. The result is presented for Cherrapunji, which is directly exposed to the southwesterly monsoon winds transporting moisture from the Bay of Bengal (Fig. 5). A simple approach to the quantification of FFT amplitude which is possible would be by the calculation of how frequently it occurs. For example, let us define the amplitude $A_{40}$ such that $40 \%$ of all amplitudes found in the FFT results are higher (which, in fact, is a kind of quantile).

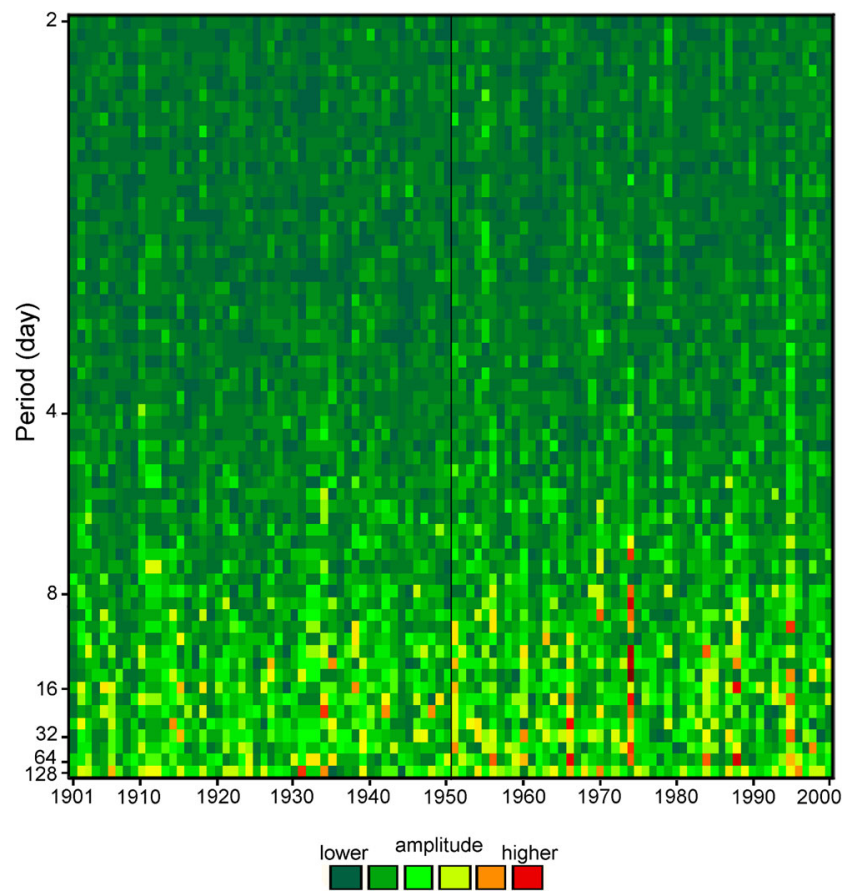

Fig. 5 Fourier transform of monsoon periods at Cherrapunji, as calculated separately for each year between 1901 and 2000 (marked boundary in 1951). The colour indicates the amplitude attributed to the harmonic components of the different frequencies (periods) 
Accordingly, in the graphical representation in Fig. 5, the amplitude $A_{40}$ is represented by a colour, such that $40 \%$ of the figure area is of that colour or more yellow or red. For Cherrapunji, the number of amplitudes above $A_{40}$ in the second half of the century is significantly higher in comparison with the first half. The significance is at the level of $z=4.0$ $(p=0.00004)$. Starting with the slightly lower amplitudes, i.e. all those higher than $A_{60}(60 \%)$, the significance is lower, $z=2.2$, and for $A_{75}, z=1.6$. For amplitude boundaries higher than $A_{40}$, for example $A_{10}$, the significance level keeps its value, even approaching $z=4.9$ at $A_{01}(1 \%$; there are 53 such amplitudes in the 1951-2000 period, as against 13 in the 1901-1950 period).

Since there are generally higher amplitudes at low frequencies (the pink noise), it would be expected that the high amplitudes counted derive from that part of the spectrum. It is true, however, that the more significant differences in the numbers of high amplitudes were obtained when the high-frequency halves of the spectrum were brought into the calculations. The most significant result comes from the calculation of the proportion of the number of high amplitudes in the two halves of the century, when only high frequencies were used (i.e. periods shorter than 4 days). This is so for amplitude $A_{06}$ and is $z=6.0$, namely there are 235 greater amplitudes in 1951-2000, as against 121 in 1901-1950. The proportion remains significant for the broad range of amplitudes, from $A_{00.1}$ to $A_{40}$.

Results such as those presented in Fig. 5 enable easy, common sense reasoning about whether some red points do, indeed, indicate the significant presence of a periodic component. Stated simply, there is no visible, consequent pattern in the form of horizontal lines lasting for a minimum of 2 years. The evident vertical lines indicate years with high rainfall. The highest annual rainfall in the twentieth century, of $22,763 \mathrm{~mm}$, was recorded at Cherrapunji in 1974. For that year, the three consecutive amplitudes prevail (Fig. 5), for quasi-periods in the range of 10-20 and 30-60 days (the period covers both upward and downward oscillation, as in the sine function). Generally, in the second half of the twentieth century, we observe a greater number of years with high amplitudes, such as in 1974 (i.e. more extreme rainfall events), and the quasiperiodicity is more pronounced for excess monsoon years.

Previous studies have shown that the 10-20-day (quasibiweekly) rainfall oscillation, associated with the westwardmoving monsoon lows generated over the Bay of Bengal, is dominant over northeast India, including the Meghalaya Hills and Bangladesh (Ohsawa et al. 2000; Murata et al. 2007), while the 30-60-day periodicity (known as the MaddenJulian oscillation, MJO) is strongest for areas located in southern India (south of $23^{\circ} \mathrm{N}$ ) (Hartmann and Michelsen 1989; Kripalani et al. 2004; Kulkarni et al. 2009). We defined excess and deficient monsoon years as one standard deviation departure from the long-term rainfall mean (1901-2000). Based on this criterion, there are 14 excess monsoons $(1918,1938$,
1951, 1954, 1960, 1963, 1964, 1970, 1974, 1984, 1987, $1988,1995,1998)$ and 11 deficient monsoons $(1904,1908$, 1909, 1925, 1944, 1957, 1961, 1962, 1967, 1978, 1980) during the period 1901-2000. Considering harmonic oscillations in the interesting ranges of $T=10-20$ days and $T=30-60$ days, it is expected that the higher amplitudes will occur in the second half of the twentieth century. This hypothesis is confirmed by $T$ test (Table 2), with not very strong, however, consistent resulting $p$ values. In excess, deficient, normal, and all monsoon years, the amplitude is higher. However, a statistically significant higher amplitude is only for all and excess monsoon years in the case of the period of 30-60 days, as well as for deficient monsoon years, for the 10-20-day periodicity. Our analysis indicates that the northward-propagating component of the 30-60-day oscillation from the equatorial Indian Ocean was more active over the Meghalaya Hills in the second half of the twentieth century. This is especially visible during extreme monsoon years.

Recently, some studies have discussed a mechanism of rainfall variation associated with an intraseasonal oscillation, through analysis of rainfall diurnal cycle. The use of a weather research and forecasting regional model revealed that the strong southwesterly winds in the lower troposphere transport moisture which triggers forced lifting and brings orographic rainfall to the southern slope of the Meghalaya Hills during the active period of quasi-biweekly oscillation, as observed also by the TRMM (Sato 2013). Moreover, the low-level jet appearing at $900 \mathrm{hPa}$ accelerates the preexisting southwesterly flow and is responsible for the evening to early morning maximum of rainfall. In contrast, low-level wind during the inactive period is too weak to reach the condensation level over the southern slope of the Meghalaya Hills. Also, the analysis of the amplitude of the diurnal cycle of rainfall shows that morning rainfall becomes 1.5 times greater than the rainfall mean during the active MJO phase in coastal areas of tropical regions (Rauniyar and Walsh 2011). In the case of India, break summer monsoon conditions (periods of deficient rainfall over the Indian subcontinent but high rainfall over northeast India) are well associated with the active MJO phases (Pai et al. 2011). Because the MJO oscillation,

Table $2 p$ value of Student's $T$ test which examines if the amplitudes of periodicity, within given limits, for monsoon periods at Cherrapunji are higher during the second half of the twentieth century (compare also Fig. 5). Statistically significant values $(\alpha=0.05)$ are in italics

\begin{tabular}{lll}
\hline Range of periods $T$ (days) & $10-20$ & $30-60$ \\
\hline All monsoon years & 0.09 & 0.036 \\
Excess monsoon years & 0.17 & 0.021 \\
Deficient monsoon years & 0.040 & 0.24 \\
Normal monsoon years & 0.14 & 0.39 \\
\hline
\end{tabular}


strongest in southern India, has been found to be gradually increasing during the last four decades of the twentieth century (Joshi and Pandey 2011), it is probable that it plays an increasing role in the presence of years with heavy rainfall over the plateau. However, to understand the influence of the MJO on the modulation of heavy rainfall over the Meghalaya Hills, further studies of the diurnal rainfall cycle are needed.

\section{Conclusions}

Analysis of daily rainfall data in the twentieth century over the Meghalaya Hills shows that, notwithstanding the general view that annual and seasonal rainfall is trendless and mainly random in nature, some significant changes in rainfall structure do, indeed, occur over an extended period of time. A weakening of the NE monsoon and strengthening of the SW monsoon are visible through the statistical analysis of the rainfall pattern in four climatic seasons during the twentieth century. The winter season is dominated by a slight but significant reduction in almost all kinds of rain events at all the stations from which data were analysed. In the pre- and post-monsoon seasons at Cherrapunji, the changes in the frequency of rainfall pattern remain those of the monsoon season, though without propagation northwards across the Meghalaya Hills. A statistically significant increase in the frequency of extreme rain events and a significant reduction in low and moderate events appear during the summer monsoon at all the three stations investigated. In effect, the contribution of the increase in heavy events is balanced by a reduction in moderate events and the monsoon mean rainfall does not show a statistically significant trend.

The interaction between large-scale monsoon circulation and the local topography plays a crucial role in determining the spatial and temporal variability of the rainfall over the Meghalaya Hills. The location of the Cherrapunji station, on the highest elevated edge of the first barrier for the summer monsoon winds, results in its position being very sensitive to a moisture influx from the adjacent Bay of Bengal. The modification of rainfall amount and spatial pattern by topography can be very strong over short distances. As a result, stations which are located leeward, especially, do not always exhibit the long-term monsoon variability over this area strongly. The above is also confirmed by our observation that the positive correlation between the stations' rainfall levels is not maintained for the highest daily rainfall.

There is no abrupt increase in the extreme rainfall over the Meghalaya Hills around 1950. However, it is a statistically significant fact that, generally, in the second half of the twentieth century, we observe a greater number of individual years with perceptible extreme rainfall events and more pronounced quasi-periodicity of 10-20 and 30-60 days. Detection of the 30-60-day rainfall periodicity, especially visible during extreme monsoon years, indicates that the northwardpropagating component of the MJO can favour the generating of extreme rainfall events over the Meghalaya Hills. Thus, the source of deep convection located in the equatorial ocean can influence atmospheric processes more northward than it was shown in previous studies.

Open Access This article is distributed under the terms of the Creative Commons Attribution License which permits any use, distribution, and reproduction in any medium, provided the original author(s) and the source are credited.

\section{References}

Alam MM, Hossain AM, Shafee S (2003) Frequency of Bay of Bengal cyclonic storms and depressions crossing different coastal zones. Int J Climato 23:1119-1125. doi:10.1002/joc.927

Breitenbach SFM, Adkins JF, Meyer H, Marwan N, Kumar KK, Haug GH (2010) Strong influence of water vapor source dynamics on stable isotopes in precipitation observed in Southern Meghalaya, NE India. Earth Planet Sc Lett 292:212-220. doi:10.1016/j.eps1.2010. 01.038

Dash SK, Kulkarni MA, Mohanty UC, Prasad K (2009) Changes in the characteristics of rain events in India. J Geophys Res 114, D10109. doi:10.1029/2008JD010572

Dash SK, Nair AA, Kulkarni MA, Mohanty UC (2011) Characteristic changes in the long and short spells of different rain intensities in India. Theor Appl Climatol 105:563-570. doi:10.1007/s00704-0110416-x

Dash SK, Sharma N, Pattnayak KC, Gao XJ, Shi Y (2012) Temperature and precipitation changes in the north-east India and their future projections. Global Planet Change 98-99:31-44. doi:10.1016/j. gloplacha.2012.07.006

Dhar ON, Farooqui SMT (1973) A study of rainfalls recorded at the Cherrapunji observatory. Hydrol Sc Bull 18:441-450

Dhar ON, Nandargi S (1995) On some characteristics of severe rainstorms of India. Theor Appl Climatol 50:205-212. doi:10.1007/ BF00866117

Dhar ON, Nandargi S (1996) Which is the rainiest station in IndiaCherrapunjee or Mawsynram? Weather 51:314-315

Dhar ON, Nandargi S (2000) A study of floods in the Brahmaputra basin in India. Int J Climatol 20:771-78

Elsner JB, Kossin JP, Jagger TH (2008) The increasing intensity of the strongest tropical cyclones. Nature 455:92-95. doi:10.1038/ nature 07234

Goswami BN, Venugopal V, Sengupta D, Madhusoodanan MS, Xavier PK (2006) Increasing trend of extreme rain events over India in a warming environment. Science 314:1442-1445. doi:10.1126/ science. 1132027

Goswami BN, Mukhopadhyay P, Mahanta R, Goswami BN (2010) Multiscale interaction with topography and extreme rainfall events in the northeast Indian. J Geophys Res 115:D12. doi:10.1029/ 2009JD012275

Guhathakurta P (2007) Highest recorded point rainfall over India. Weather 62:349. doi:10.1002/wea.154

Guhathakurta P, Rajeevan M (2008) Trends in rainfall pattern over India. Int J Climatol 28:1453-1469. doi:10.1002/joc.1640

Guhathakurta P, Sreejith OP, Menon PA (2011) Impact of climate change on extreme rainfall events and flood risk in India. J Earth Syst Sc 120:359-373

Hartmann DL, Michelsen ML (1989) Intraseasonal periodicities in Indian rainfall. J Atmos Sc 46:2838-2862 
Hennessey KJ, Gregory JM, Mitchell JFB (1997) Changes in daily precipitation under enhanced greenhouse conditions. Clim Dyn 13: $667-680$

Hofer T (1997) Floods in Bangladesh: a highland-lowland interaction? Geographica Bernensia G48. University of Bern, Switzerland, Institute of Geography

Hofer T, Messerli B (2006) Floods in Bangladesh: history, dynamics and rethinking the role of the Himalayas. United Nations University Press, Tokyo

India Meteorological Department (2008) Tracks of storms and depressions in the Bay of Bengal and the Arabian Sea 1877-1970. Cyclone eAtlas - IMD, Regional Meteorological Centre, Chennai

IPCC (Intergovernmental Panel on Climate Change) (2007) The physical science basis. In: Solomon S (ed) Contribution of Working Group I to the Fourth Assessment Report of the Intergovernmental Panel on Climate Change. Cambridge University Press, Cambridge

Jain SK, Kumar V, Saharia M (2013) Analysis of rainfall and temperature trends in northeast India. Int J Climatol 33:968-978. doi:10.1002/joc. 3483

Jennings AH (1950) World's greatest observed point rainfalls. Mon Wea Rev 78:4-5

Joshi MK, Pandey AC (2011) Trend and spectral analysis of rainfall over India during 1901-2000. J Geophys Res 116, D06104. doi:10.1029/ 2010JD014966

Kishtawal CM, Niyogi D, Telari M, Roger A, Pielke RA Sr, Shepherd JM (2010) Urbanization signature in the observed heavy rainfall climatology over India. Int J Climatol 30:19081916. doi: $10.1002 /$ joc. 2044

Kitoh AS, Yukimoto NA, Motoi T (1997) Simulated changes in the Asian summer monsoon at times of increased atmospheric $\mathrm{CO}_{2} . \mathrm{J}$ Meteorol Soc Jpn 75:1019-1031

Kripalani RH, Kulkarni A, Sabade SS, Revadekar JV, Patwardhan SK, Kulkarni JR (2004) Intra-seasonal oscillations during monsoon 2002 and 2003. Current Sc 87:325-334

Krishna KM (2009) Intensifying tropical cyclones over the North Indian Ocean during summer monsoon-global warming. Global Planet Change 65:12-16. doi:10.1016/j.gloplacha.2008.10.007

Kulkarni A, Sabade SS, Kripalani RH (2009) Spatial variability of intraseasonal oscillations in extreme Indian monsoons. Int J Climatol 29: 1945-1955

Medina S, Houze RA, Kumar A, Niyogi D (2010) Summer monsoon convection in the Himalayan region: terrain and land cover effects. Q J R Meteorol Soc 136:593-616. doi:10.1002/qi.601

Meehl GA, Zwiers F, Evans J, Knutson T, Mearns L, Whetton P (2000) Trends in extreme weather and climate events: issues related to modeling extremes in projections of future climate change. Bull Am Meteorol Soc 81:427-436

Mitra C, Shepherd JM, Jordan T (2012) On the relationship between the premonsoonal rainfall climatology and urban land cover dynamics in Kolkata city, India. Int J Climatol 32:1443-1454. doi:10.1002/ joc. 2366

Mooley DA, Shukla J (1987) Variability and forecasting of the summer monsoon rainfall over India. In: Chang CP, Krishnamurti TN (eds) Monsoon meteorology. Oxford University Press, New York, pp 26-59

Murata F, Hayashi T, Matsumoto J, Asada H (2007) Rainfall on the Meghalaya plateau in northeastern India - one of the rainiest places in the world. Nat Hazards 42:391-399. doi:10.1007/s11069-0069084-z

Murata F, Terao T, Hayashi T, Asada H, Matsumoto J (2008) Relationship between atmospheric conditions at Dhaka, Bangladesh, and rainfall at Cherrapunjee, India. Nat Hazards 44:399-410. doi:10.1007/ s11069-007-9125-2

Ohsawa T, Hayashi T, Mitsuta Y, Matsumoto J (2000) Intraseasonal variation of monsoon activities associated with the rainfall over
Bangladesh during the 1995 summer monsoon season. J Geophys Res 105(D24):29445-29459

Pai DS, Bhate J, Sreejith OP, Hatwar HR (2011) Impact of MJO on the intraseasonal variation of summer monsoon rainfall over India. Clim Dyn 36:41-55. doi:10.1007/s00382-009-0634-4

Parthasarathy B, Sontakke NA, Munot AA, Kothawale DR (1987) Droughts/floods in the summer monsoon season over different meteorological subdivisions of India for period 1871-1984. J Climatol 7:57-70

Parthasarathy B, Munot AA, Kothawale DR (1995) Monthly and seasonal time series for all India, homogeneous regions and meteorological subdivisions: 1871-1994, Res. Rep. RR-065, Indian Institute of Tropical Meteorology, Pune, India, pp. 1-113.

Prokop P, Walanus A (2003) Trend and periodicity in the longest instrumental rainfall series for the area of most extreme rainfall in the world, northeast India. Geogr Polonica 76(2): $25-35$

Rajeevan M, Bhate J, Jaswal AK (2008) Analysis of variability and trends of extreme rainfall events over India using 104 years of gridded daily rainfall data. Geophys Res Lett 35, L18707. doi:10.1029/2008GL035143

Rakhecha PR, Soman MK (1994) Trends in the annual extreme rainfall events of 1 to 3 days duration over India. Theor Appl Climatol 48: 227-237

Rao YP (1981a) The climate of the Indian subcontinent. In: Takahasi K, Arakawa H (eds) World survey of climatology 9. Elsevier, Amsterdam, pp 67-182

Rao KN (1981b) Tropical cyclones of the Indian seas. In: Takahasi K, Arakawa H (eds) World survey of climatology 9. Elsevier, Amsterdam, pp 257-280

Rauniyar SP, Walsh KJE (2011) Scale interaction of the diurnal cycle of rainfall over the maritime continent and Australia: influence of the MJO. J Climate 24:325-348. doi:10.1175/2010JCLI3673.1

Romatschke U, Houze RAJ (2011a) Characteristics of precipitating convective systems in the premonsoon season of South Asia. J Hydromet 12:157-180. doi:10.1175/2010JHM1311.1

Romatschke U, Medina S, Houze RAJ (2010) Regional, seasonal, and diurnal variations of extreme convection in the South Asian Region. J Climate 23:419-439

Romatschke U, Houze RAJr (2011b) Characteristics of precipitating convective systems in the South Asian monsoon. J Hydromet 12: 3-26. doi:10.1175/2010JHM1289.1

Roy S, Balling RC (2004) Trends in extreme daily precipitation indices in India. Int J Climatol 24:457-466. doi:10.1002/joc.995

Sato T (2013) Mechanism of orographic precipitation around the Meghalaya Plateau associated with intraseasonal oscillation and the diurnal cycle. Mon Wea Rev 141:2451-2466. doi:10.1175/ MWR-D-12-00321.1

Singh OP, Ali Khan TM, Rahman MS (2000) Changes in the frequency of tropical cyclones over the north Indian Ocean. Meteorol Atmos Phys 75:11-20

Singh S, Hayashi T, Syiemlieh HJ, Cajee L, Terao T (2011) Weather variability and rainfall pattern of Sidr, the post-monsoon cyclonic storm of 15 November 2007 in the Meghalaya Plateau, India. Current Sc 100:1522-1531

Soja R, Starkel L (2007) Extreme rainfalls in Eastern Himalaya and southern slope of Meghalaya Plateau and their geomorphologic impacts. Geomorphology 84:170-180. doi:10.1016/j.geomorph. 2006.01.040

Sontakee NA, Singh N (1996) Longest instrumental regional and allIndia summer monsoon rainfall series using optimum observations: reconstruction and update. Holocene 6:315-331

Starkel L, Singh S (eds) (2004) Rainfall, runoff and soil erosion in the globally extreme humid area, Cherrapunji region, India. Prace Geograficzne 191. IGiPZ PAN, Warszawa 
Subbaramayya I, Rao SRM (1984) Frequency of Bay of Bengal cyclones in the post-monsoon season. Mon Wea Rev 112:1640-1642

Terao T, Islam MN, Murata F, Hayashi T (2008) High temporal and spatial resolution observations of meso-scale features of pre- and mature summer monsoon cloud systems over Bangladesh. Nat Hazards 44:341-351. doi:10.1007/s11069-007-9128-z

Thapliyal V, Kulshrestha SM (1992) Which is the rainiest place in the world? Mausam 43:331-332

Trenberth KE, Dai A, Rasmussen RM, Parsons DB (2003) The changing character of precipitation. Bull Am Meteorol Soc 84:1205-1217. doi:10.1175/BAMS-84-9-1205
Vittal H, Karmakar S, Ghosh S (2013) Diametric changes in trends and patterns of extreme rainfall over India from pre-1950 to post-1950. Geophys Res Lett 40:3253-3258. doi:10.1002/grl.50631

Webster PJ, Holland GJ, Curry JA, Chang HR (2005) Changes in tropical cyclone number, duration, and intensity in a warming environment. Science 309:1844-1846. doi:10.1126/science. 1116448

Yamane Y, Hayashi T, Dewan AM, Fatima F (2010) Severe local convective storms in Bangladesh: part I. Climatology. Atmos Res 95: 400-406. doi:10.1016/j.atmosres.2009.11.004 